\title{
Midterm results of mitral valve repair for atrial functional mitral regurgitation: a retrospective study
}

Daisuke Kaneyuki, Hiroyuki Nakajima, Toshihisa Asakura, Akihiro Yoshitake, Chiho Tokunaga, Masato Tochii, Jun Hayashi, Akitoshi Takazawa, Hiroaki Izumida and Atsushi Iguchi

\begin{abstract}
Background: Annular dilation by left atrial remodeling is considered the main cause of atrial function mitral regurgitation. Although acceptable outcomes have been obtained using mitral ring annuloplasty alone for atrial functional mitral regurgitation, data assessing outcomes of this procedure are limited. Therefore, we aimed to assess midterm outcomes of mitral valve repair in patients with atrial functional mitral regurgitation.

Methods: We retrospectively studied 40 patients (mean age: $69 \pm 9$ years) who had atrial fibrillation that persisted for $>1$ year, preserved left ventricular ejection fraction of $>40 \%$, and mitral valve repair for atrial functional mitral regurgitation. The mean clinical follow-up duration was $42 \pm 24$ months.

Results: Mitral ring annuloplasty was performed for all patients. Additional repair including anterior mitral leaflet neochordoplasty was performed for 22 patients. Concomitant procedures included maze procedure in 20 patients and tricuspid ring annuloplasty in 31 patients. Follow-up echocardiography showed significant decreases in left atrial dimensions and left ventricular end-diastolic dimensions. Recurrent mitral regurgitation due to ring detachment or leaflet tethering was observed in five patients and was seen more frequently among those with preoperative left ventricular dilatation. Three patients without tricuspid ring annuloplasty or sinus rhythm recovery by maze procedure developed significant tricuspid regurgitation. Five patients who underwent the maze procedure showed sinus rhythm recovery. Rates of freedom from re-admission for heart failure at 1 and 5 years after surgery were 95 and 86\%, respectively.

Conclusions: Mitral valve repair is not sufficient to prevent recurrent atrial functional mitral regurgitation in patients with preoperative left ventricular dilatation. Tricuspid ring annuloplasty may be required for long-term prevention of significant tricuspid regurgitation.
\end{abstract}

Keywords: Atrial functional mitral regurgitation, Atrial fibrillation, Mitral valve repair, Tricuspid ring annuloplasty, Maze procedure

\footnotetext{
* Correspondence: kinkoudaisuke@gmail.com
}

Division of Cardiovascular Surgery, Saitama Medical University International

Medical Center, 1397-1, Yamane, Hidaka-shi, Saitama 3501298, Japan

(C) The Author(s). 2020 Open Access This article is licensed under a Creative Commons Attribution 4.0 International License, which permits use, sharing, adaptation, distribution and reproduction in any medium or format, as long as you give appropriate credit to the original author(s) and the source, provide a link to the Creative Commons licence, and indicate if changes were made. The images or other third party material in this article are included in the article's Creative Commons licence, unless indicated otherwise in a credit line to the material. If material is not included in the article's Creative Commons licence and your intended use is not permitted by statutory regulation or exceeds the permitted use, you will need to obtain permission directly from the copyright holder. To view a copy of this licence, visit http://creativecommons.org/licenses/by/4.0/ The Creative Commons Public Domain Dedication waiver (http://creativecommons.org/publicdomain/zero/1.0/) applies to the data made available in this article, unless otherwise stated in a credit line to the data. 


\section{Background}

Left atrial (LA) dilatation and corresponding mitral annular dilatation due to long-standing atrial fibrillation (AF) may cause mitral regurgitation (MR) without left ventricular (LV) dilatation and dysfunction. This secondary functional MR has been recognized as atrial functional MR [1-5]. As annular dilation by LA remodeling has been considered the main cause of atrial function MR, mitral ring annuloplasty has been the main target of surgical intervention. However, the number of studies reporting outcomes of surgical treatment for atrial functional MR is limited [6-10]. Thus, we aimed to review the midterm outcomes of mitral valve (MV) repair for atrial functional MR.

\section{Methods}

\section{Baseline characteristics}

We retrospectively studied 40 patients who underwent MV repair for atrial functional MR between January 2011 and December 2018 at the Saitama Medical University International Medical Center (mean age, $69 \pm 9$ years; $68 \%$ male $(n=27))$. All patients had long-standing AF that had persisted for more than 1 year, preserved LV ejection fraction (>40\%), and moderate to severe functional MR. Patients with organic valvular heart disease, including rheumatic or degenerative MV disease, a history of coronary artery disease, LV wall motion abnormality, or a history of prior cardiac surgery were excluded from the study because these conditions may confound the results. The patients' preoperative characteristics are shown in Table 1.

\section{Echocardiography}

The LA dimension, LV end-diastolic dimension, LV endsystolic dimension, and LV ejection fraction were measured [11]. The MR grade was evaluated using a multiparametric approach, including assessment of the Doppler-derived jet, effective regurgitant orifice area, MR volume and fraction, and pulmonary vein flow velocity pattern $[12,13]$. The tricuspid regurgitation (TR) grade was also defined using a

Table 1 Preoperative patient characteristics $(n=40)$

\begin{tabular}{ll}
\hline Covariate & Mean \pm SD or Number (\%) \\
\hline Demographics & $69 \pm 9$ \\
Age, years & $27(68)$ \\
Male sex & $3(8)$ \\
New York Heart Association class III/IV & \\
Comorbidities & $23(58)$ \\
Systemic hypertension & $6(15)$ \\
Diabetes mellitus & $3(8)$ \\
Chronic obstructive pulmonary disease & $15(38)$ \\
Chronic kidney disease & $2(5)$ \\
Cerebrovascular events &
\end{tabular}

SD Standard deviation multiparametric approach $[12,13]$. Pseudoprolapse of the anterior mitral leaflet (AML) was defined when there was a gap between the AML and the posterior mitral leaflet (PML) due to atriogenic PML tethering $[8,10,14,15]$

\section{Surgical technique}

Through median sternotomy, cardiopulmonary bypass was established using ascending aortic and bicaval cannulation. After sizing the intercommissural distance and AML area, an annuloplasty ring or band [semirigid Future annuloplasty band $(n=1)$, Medtronic, Minneapolis, MN; Carpentier-Edwards Physio Ring II, Edwards Lifesciences, Irvine, CA $(n=34)$; Cosgrove annuloplasty band $(n=3)$, Edwards Lifesciences; or Profile 3D $(n=2)$, Medtronic] was implanted with interrupted 2-0 Ethibond sutures. In the first half of this study, undersized ring annuloplasty was performed to address annular dilatation and increase the coaptation length. Once we understood the mechanisms of atrial functional MR, we performed true-sized ring annuloplasty to prevent aggravation of PML tethering. In the latter half of the present study, we used only a semi-rigid ring (Carpentier-Edwards Physio Ring II) larger than $28 \mathrm{~mm}$. If AML pseudoprolapse existed, AML neochordoplasty was added. A pair of artificial neochordae with 4-0 or 5-0 polytetrafluoroethylene sutures (Gore-Tex sutures, W.L. Gore \& Associates, Newark, DE) was placed at A2 from the anterolateral and posteromedial papillary muscle. Then, the length of the neochordae was adjusted after mitral ring annuloplasty until residual MR was diminished on water saline test. Concomitant tricuspid annuloplasty was performed in patients with severe TR, or mild or moderate TR with a dilated annulus $\left(\geq 40 \mathrm{~mm}\right.$ or $>21 \mathrm{~mm} / \mathrm{m}^{2}$ by transthoracic echocardiography) [16]. A tricuspid annuloplasty ring [MC3 ring $(n=17)$, Edwards Lifesciences; Physio Tricuspid annuloplasty ring $(n=10)$, Edwards Lifesciences; Contour 3D annuloplasty ring $(n=3)$, Medtronic; or a TriAd Adams tricuspid annuloplasty ring $(n=1)$, Medtronic] was implanted with interrupted $2-0$ Ethibond sutures. The indication of the maze procedure and LA plication was decided at surgeon's discretion based on the period of atrial fibrillation and the size of LA.

\section{Follow-up}

Clinical follow-up examinations were completed for all patients. The mean follow-up period was $42 \pm 24$ months. Follow-up echocardiography was performed 1 week after surgery and every year after discharge. The mean echocardiographic follow-up period was $26 \pm 24$ months.

\section{Statistical analyses}

Descriptive statistics were reported as the mean \pm standard deviation for continuous variables and as frequencies and percentages for categorical variables unless otherwise noted. A comparison between the groups was performed using 
Student's $t$ test or Wilcoxon-Mann-Whitney $U$-test for continuous variables and the chi-square or Fisher's exact test for categorical variables. Event-free rates were estimated using Kaplan-Meier analysis. $P$-values $<0.05$ were considered to indicate statistical significance. Statistical analyses were performed using JMP software (version 14.1.0; SAS institute, Cary, NC).

\section{Results}

\section{Echocardiographic outcomes}

The mean LV end-systolic dimension and mean LV ejection fraction did not significantly change between the preoperative period and the follow-up period. The mean LA dimension significantly decreased from the preoperative period $(60 \pm 11 \mathrm{~mm})$ to the follow-up period $(54 \pm 13 \mathrm{~mm}$, $p<0.001)$. The mean LV end-diastolic dimension significantly decreased from the preoperative period ( $55 \pm 7$ $\mathrm{mm})$ to the follow-up period $(51 \pm 8 \mathrm{~mm}, p<0.001)$.

All patients were discharged with an MR grade no greater than mild, except one patient with moderate MR. During the follow-up period, four patients developed moderate or severe MR. Two patients with end-stage renal disease who underwent mitral ring annuloplasty alone with a 26-mm Cosgrove annuloplasty band and a 28-mm Physio Ring II developed severe MR due to partial detachment of prosthetic rings. Other patients developed moderate or severe MR due to PML tethering (Table 2). One of these patients underwent mitral ring annuloplasty with PML augmentation and basal chordae resection. Two other patients underwent mitral ring annuloplasty with AML neochordoplasty on initial surgery.

Table 3 shows the preoperative transthoracic echocardiography data of patients who developed recurrent MR $(n=$ $5)$ and those without MR recurrence $(n=35)$. Mean LA dimensions, mean LV end-diastolic dimensions, and mean LV end-systolic dimensions were significantly larger in patients with recurrent MR than in patients without recurrent MR.

Receiver-operating characteristic curves were used to evaluate the cutoff values of LV end-diastolic dimensions as a preoperative predictor for recurrent moderate or severe MR. LV end-diastolic dimensions of $61 \mathrm{~mm}$ had a sensitivity of $91 \%$ and a specificity of $80 \%$ for predicting recurrent moderate or severe MR. The area under the curve for LV end-diastolic dimensions was 0.897 (Fig. 1).

Moderate or severe TR was found in 22 patients preoperatively. All patients were discharged with a TR grade no greater than mild. However, among five patients without tricuspid ring annuloplasty or sinus recovery by maze procedure, three patients developed moderate or severe recurrent TR during the follow-up period.

\section{Perioperative data}

All patients underwent mitral ring annuloplasty. The median size of the implanted ring was $28 \mathrm{~mm}$ (range: 24-32 mm). As determined by intraoperative observation, mechanisms of MR included annular dilatation alone in 19 patients and annular dilatation with AML pseudoprolapse in 19 patients. Additional MV repair was performed for 22 patients, which included AML neochordoplasty in 19 patients, PML augmentation in 3, and basal chordae resection in 2. Other concomitant procedures included the maze procedure in 20 patients, tricuspid ring annuloplasty in 31, and LA plication in 9 . These data are summarized in Table 4 .

\section{Clinical outcomes}

There were no cases of in-hospital mortality. Postoperative complication included acute renal failure requiring hemodialysis in two patients, re-exploration for bleeding in one patient, and stroke in one patient. Among the 20 patients who underwent the maze procedure, sinus rhythm was recovered in five patients (25\%).

During the follow-up period, one patient experienced stroke due to infective endocarditis resulting in heart failure, seven patients required re-admission because of worsening heart failure, and six patients required permanent pacemaker implantation for sick sinus syndrome. Among five patients with recurrent MR, two patients with ring detachment required reoperation for prosthetic valve replacement 37 months and 63 months after initial operations. Seven patients died during the follow-up period because of congestive heart failure (four patients) and pneumonia (three patients) (Table 5). The rates of freedom from recurrent MR were $97.1 \%$ at 1 year, $85.4 \%$ at 3 years, and $62.3 \%$

Table 2 Preoperative and follow-up echocardiographic data $(n=40)$

\begin{tabular}{llll}
\hline & Preoperative data & Follow-up data & $\boldsymbol{P}$ value \\
\hline LA dimension (mm) & $60 \pm 11$ & $54 \pm 13$ & $<.001^{*}$ \\
LV end-diastolic dimension (mm) & $55 \pm 7$ & $51 \pm 8$ & $<.001^{*}$ \\
LV end-systolic dimension (mm) & $37 \pm 7$ & $36 \pm 9$ & 0.30 \\
Ejection fraction (\%) & $60 \pm 11$ & $57 \pm 15$ & 0.13 \\
Moderate or severe MR & 40 & 5 & 3 \\
Moderate or severe TR & 22 & & \\
\hline
\end{tabular}

LA Left atrial, $L V$ Left ventricular, MR Mitral regurgitation, TR Tricuspid regurgitation ${ }^{*}$ statistically significant 
Table 3 Preoperative echocardiographic data for patients with and without recurrent MR $(n=40)$

\begin{tabular}{llll}
\hline & Recurrent MR (+) & Recurrent MR (-) & P value \\
\hline LA dimension (mm) & $71 \pm 12$ & $59 \pm 9$ & $\mathbf{0 . 0 0 8}^{*}$ \\
LV end-diastolic dimension (mm) & $64 \pm 3$ & $54 \pm 1$ & $\mathbf{0 . 0 0 1 *}^{*}$ \\
LV end-systolic dimension (mm) & $43 \pm 3$ & $36 \pm 1$ & $\mathbf{0 . 0 3 4 ^ { * }}$ \\
Ejection fraction (\%) & $60 \pm 5$ & $60 \pm 2$ & 0.91 \\
\hline
\end{tabular}

LAD Left atrial, $L V$ Left ventricular, MR Mitral regurgitation

*statistically significant

at 5 years after surgery (Fig. 2). The rates of freedom from re-admission for heart failure were $94.9 \%$ at 1 year, $85.7 \%$ at 3 years, and $85.7 \%$ at 5 years after surgery (Fig. 3).

\section{Discussion}

This study investigated midterm outcomes after MV repair for atrial functional MR. Although atrial functional MR was shown to have been repaired successfully on postoperative echocardiography, some patients with preoperative LV dilatation developed recurrent MR due to prosthetic ring detachment or PML tethering during the follow-up period resulting in heart failure and cardiac death. In addition, only $25 \%(5 / 20)$ of the patients who underwent maze procedures showed sinus rhythm recovery, and $60 \%(3 / 5)$ of the patients without sinus rhythm recovery or tricuspid ring annuloplasty developed moderate or severe TR.

Atrial functional MR can be mitigated using sinus rhythm restoration strategies via reverse LA anatomical

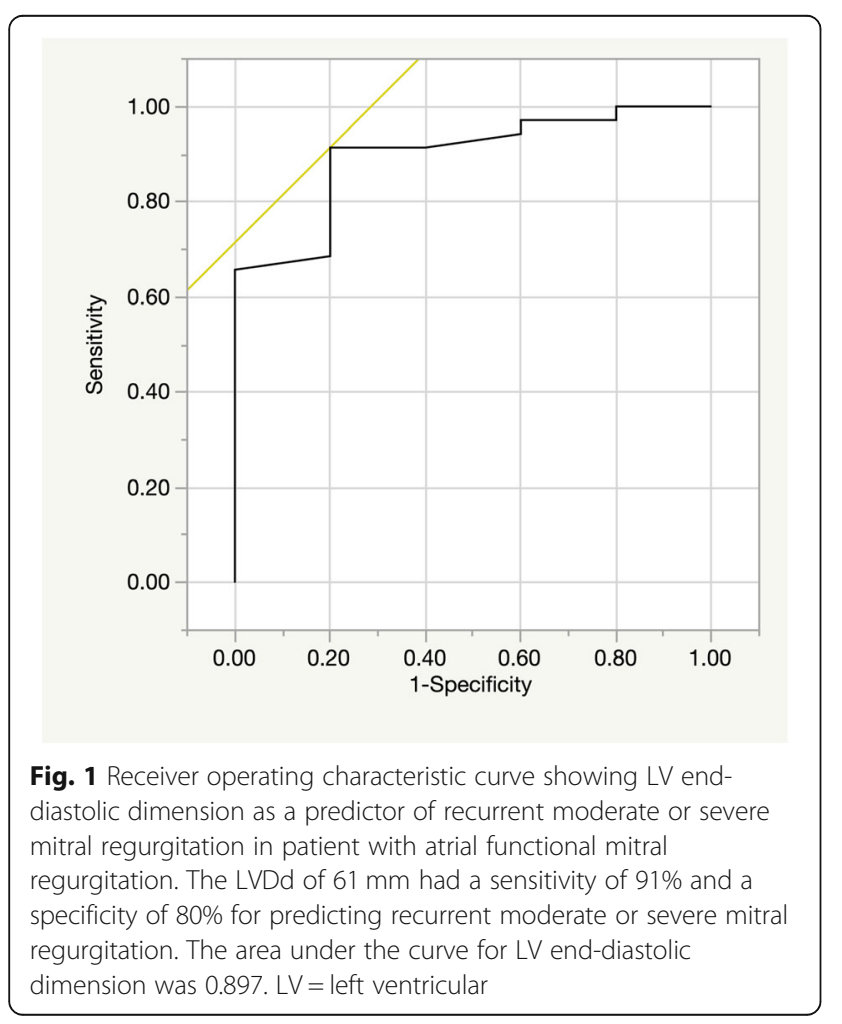

and mechanical remodeling [17]. Some patients, especially with a giant LA and long-standing AF may be refractory to catheter ablation. As the LA volume continues to increase with persistent $\mathrm{AF}$, patients can develop congestive heart failure that cannot be managed with medications. Although surgical indication for atrial functional MR remains uncertain, surgical intervention has been reported to be beneficial for decreasing LA volume, severity of MR, and clinical symptoms in heart failure [6-10]. In addition, this study showed decreased LA dimension and LV enddiastolic dimension on follow-up echocardiography.

The main surgical strategy for atrial functional MR was to repair mitral annular dilatation with ring annuloplasty. Five patients developed recurrent MR during the postoperative and follow-up periods. One cause of recurrent $\mathrm{MR}$ was prosthetic ring detachment, which was common in patients with end-stage renal disease. Because expansion of the LA wall leads to deviation of the posterior annulus toward the outside of the myocardium $[18,19]$, placing the sutures correctly within the posterior annulus may be challenging. Further, LA and mitral annular dilatation worsened if AF was sustained in this study. This may increase the tension between the prosthetic ring and the posterior mitral annulus. Another cause of recurrent MR was PML tethering. Although AML neochordoplasty, PML augmentation, and basal

Table 4 Operative patient characteristics $(n=40)$

\begin{tabular}{ll}
\hline Covariate & Mean \pm SD or Number (\%) \\
\hline Median annuloplasty ring size (range) & $28(24-34) \mathrm{mm}$ \\
Mitral valve procedures & $19(48)$ \\
Mitral ring annuloplasty only & $19(48)$ \\
Anterior mitral leaflet neochordoplasty & $3(8)$ \\
Posterior mitral leaflet augmentation & $2(5)$ \\
Basal chordae resection & \\
Concomitant procedures & $20(50)$ \\
Maze procedures & $31(78)$ \\
Tricuspid ring annuloplasty & $9(23)$ \\
Left atrial plication & $177 \pm 38 \mathrm{~min}$ \\
Cardiopulmonary bypass time & $134 \pm 31 \mathrm{~min}$ \\
Cross-clamp time &
\end{tabular}


Table 5 Early and midterm clinical outcomes $(n=40)$

\begin{tabular}{ll}
\hline Covariate & Mean \pm SD or Number (\%) \\
\hline Early outcomes & 0 \\
In-hospital mortality & $2(5)$ \\
Acute renal failure requiring hemodialysis & $1(3)$ \\
Re-exploration for bleeding & $1(3)$ \\
Cerebrovascular events & 0 \\
Deep sternal wound infection & $7(18)$ \\
Midterm outcomes & $4(10)$ \\
Patient deaths during the follow-up period & 5 (13) \\
Cardiac death & $7(18)$ \\
Recurrent moderate or severe MR & $1(3)$ \\
Re-admission for heart failure & $2(5)$ \\
Cerebrovascular events & $6(15)$ \\
Reoperation for recurrent MR & $1(3)$
\end{tabular}

MR Mitral regurgitation, SD Standard deviation

chordal resection was performed to repair AML pseudoprolapse or atriogenic PML tethering, recurrent MR due to PML tethering was not completely prevented. This study revealed that preoperative echocardiography in patients with recurrent MR showed LV dilatation. This finding was in line with that of a previous study [9]. LV dilatation is a morphological change in the late phase of atrial functional MR. Therefore, surgical intervention before the late phase may be beneficial. Otherwise further additional repair including subvalvular apparatus procedures or mitral valve replacement may be required in patients in the late phase of atrial functional MR.
Long-standing AF is also known to cause functional secondary TR due to tricuspid annular dilatation [20]. Takahashi et al. suggested that MV repair in addition to tricuspid valve repair should be considered because atrial functional MR and TR are dual-valve diseases [10]. The present study showed that $60 \%$ of the patients without tricuspid ring annuloplasty or sinus rhythm recovery using the maze procedure developed moderate or severe TR during the follow-up period. Because the efficacy of the maze procedure in patients with significant LA dilatation was limited [21], tricuspid ring annuloplasty should be performed in addition to MV repair for atrial functional MR.

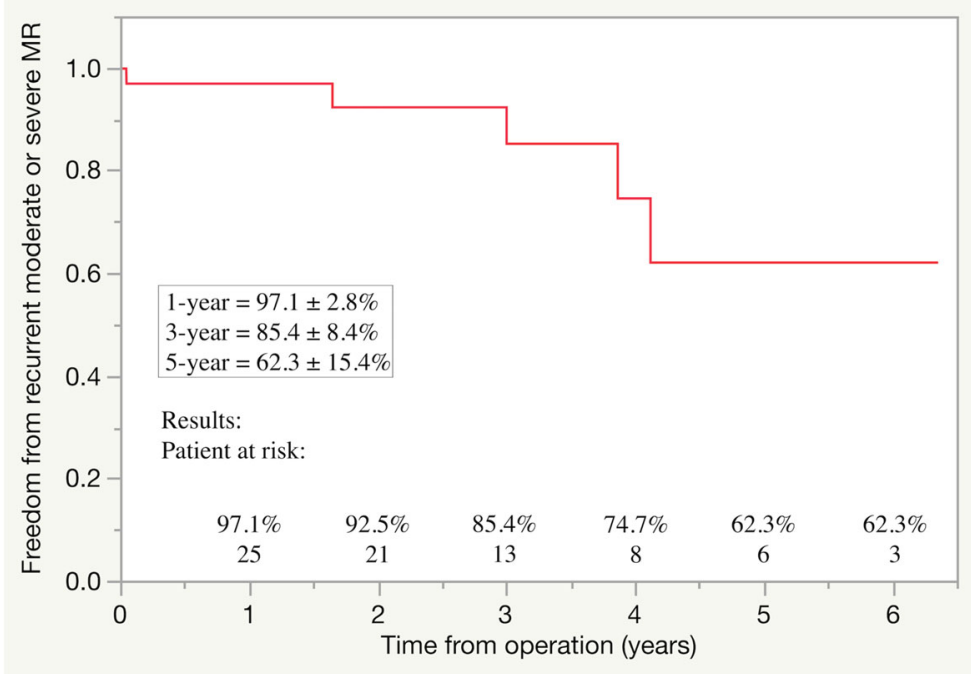

Fig. 2 Freedom from recurrent moderate or severe mitral regurgitation (MR) 


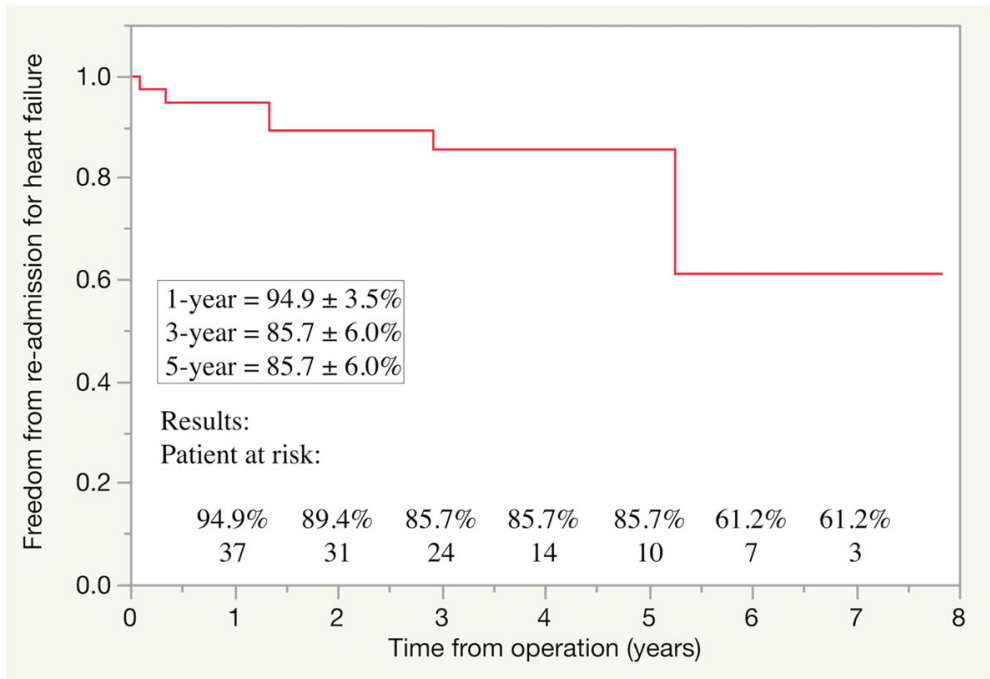

Fig. 3 Freedom from re-admission for heart failure

The indication of the maze procedure for patients with atrial functional MR remains unclear. Patients with a giant LA and long-standing AF who are refractory to catheter ablation are also usually refractory to the maze procedure. However, restoration of sinus rhythm is the fundamental treatment for atrial functional MR and some patients can receive benefits from the maze procedure. The balance of benefits and risks of the maze procedure should be taken into consideration, and further study should elucidate the reasonable indication of the maze procedure. Although the indication of LA plication also remains unclear, Takahashi et al. [10] reported that one patient showed a gradual increase in the LA volume index, and this resulted in re-worsening of the PML tethering. Therefore, LA plication might prevent further PML tethering. In addition, Wang et al. [22] showed that overall restoration of sinus rhythm was significantly improved in the group with aggressive reduction of LA wall tension during a 1-year clinical follow-up. They concluded that aggressive LA size reduction might be a key factor for maintenance of sinus rhythm after the maze procedure. Because sinus rhythm recovery is one of key factors to prevent atrial functional MR progression, LA plication may be beneficial.

\section{Limitations}

This study has several limitations. This was a singlecenter, retrospective observational study with a small number of patients. The use of multiple mitral annuloplasty rings was a major confounding variable. All control subjects underwent additional MV repair for AML pseudoprolapse or PML tethering. Thus, studies with longer follow-up periods and more statistical power are essential to validate the performance of additional MV repair for atrial functional MR. Moreover, echocardiographic studies using transesophageal echocardiography with threedimensional morphological analysis are warranted to acquire more accurate data and to elucidate further mechanisms of recurrent MR. Finally, this study included patients with preoperative LV dilatation, which may be associated with ventriculogenic tethering. Although some argue that atriogenic and ventriculogenic should be differentiated, there is still no clear definition of atrial functional $\mathrm{MR}$, and we believe that LV dilatation is one mechanism underlying the severe form of atrial functional MR. Therefore, studying the entire spectrum of atrial functional MR is crucial to elucidate the optimal surgical timing and technique.

\section{Conclusions}

Our analysis suggests that recurrent MR due to prosthetic ring detachment or PML tethering occurred even after mitral ring annuloplasty with additional repair techniques in patients with atrial functional MR and preoperative LV dilatation. Because sinus rhythm recovery was not sufficient after the maze procedure in patients with severe LA dilatation, tricuspid ring annuloplasty is recommended for patients without considerable operative risk.

\section{Abbreviations \\ AF: Atrial fibrillation; AML: Anterior mitral leaflet; LA: Left atrium; LV: Left ventricle; MR: Mitral regurgitation; MV: Mitral valve; PML: Posterior mitral leaflet; TR: Tricuspid regurgitation}

\section{Acknowledgments}

Not applicable.

\section{Authors' contributions}

DK contributed to concept/design; drafted the manuscript; and performed data analysis/interpretation, statistical analysis, and data collection. HN 
contributed to the critical revision of the manuscript. All authors read and approved the final manuscript.

\section{Funding}

Not applicable.

\section{Availability of data and materials}

The datasets used and analyzed during the current study are available from the corresponding author on reasonable request.

\section{Ethics approval and consent to participate}

In compliance with the declaration of Helsinki, the local ethics committee approved this study (date and IRB approval number: January 9, 2019, 18220). Individual consent for the study was waived, as data acquisition was performed in an anonymized manner.

\section{Consent for publication}

Not applicable.

\section{Competing interests}

The authors declare that they have no competing interests.

Received: 11 June 2020 Accepted: 5 October 2020

Published online: 12 October 2020

\section{References}

1. Sanfilippo AJ, Abascal VM, Sheehan M, Oertel LB, Harrigan P, Hughes R, et al. Atrial enlargement as a consequence of atrial fibrillation. A prospective echocardiography study. Circulation. 1990;82:792-7.

2. Tanimoto M, Pai RG. Effect of isolated left atrial enlargement on mitral annular size and valve competence. Am J Cardiol. 1996;77:769-74

3. Kihara T, Gillinov AM, Takasaki K, Fukuda S, Song JM, Shiota M, et al. Mitral regurgitation associated with mitral annular dilation in patients with lone atrial fibrillation: an echocardiographic study. Echocardiography. 2009;26: $885-9$.

4. Ring L, Dutka DP, Wells FC, Fynn SP, Shapiro LM, Rana BS. Mechanisms of atrial mitral regurgitation: insights using 3D transesophageal echo. Eur Heart J Cardiovasc Imaging. 2014;15:500-8.

5. Van Rosendael PJ, Katsanos S, Kamperidis V, Roos CJ, Scholte AJ, Schalij MJ, et al. New insights on carpentier I mitral regurgitation from multidetector row computed tomography. Am J Cardiol. 2014;114:763-8.

6. Kilic A, Schwartzman DS, Subramaniam K, Zenati MA. Severe functional mitral regurgitation arising from isolated annular dilatation. Ann Thorac Surg. 2010;90:1343-5.

7. Vohra HA, Whistance RN, Magan A, Sadeque SA, Livesey SA. Mitral valve repair for severe mitral regurgitation secondary to lone atrial fibrillation. Eur J Cardiothorac Surg. 2012:42:634-7.

8. Takahashi Y, Abe Y, Sasaki Y, Bito Y, Morisaki A, Nishimura S, et al. Mitral valve repair for atrial functional mitral regurgitation in patients with chronic atrial fibrillation. Interact Cardiovasc Thorac Surg. 2015;21:163-8.

9. Sakaguchi T, Totsugawa T, Orihashi K, Kihara K, Tamura K, Hiraoka A, et al. Mitral annuloplasty for atrial functional mitral regurgitation in patients with chronic atrial fibrillation. J Card Surg. 2019;34:767-73.

10. Takahashi Y, Abe Y, Takashi M, Fujii H, Morisaki A, Nishimura S, et al. Mid term results of valve repairs for atrial functional mitral and tricuspid regurgitations. Gen Thorac Cardiovasc Surg. 2020;68:467-76.

11. Lang RM, Bierig M, Devereux RB, Flachskampf FA, Foster E, Pellikka PA, et al. Recommendations for chamber quantification: a report from the American Society of Echocardiography's guidelines and standards committee and the chamber quantification writing group, developed in conjunction with the European Association of Echocardiography, a branch of the European Society of Cardiography. J Am Soc Echocardiogr. 2005;18:1440-63.

12. Nishimura RA, Otto CM, Bonow RO, Carabello BA, Erwin JP 3rd, Guyton RA et al. 2014 AHA/ACC guideline for the management of patients with valvular heart disease: a report of the American College of Cardiology/ American Heart Association task force on practice guidelines. Circulation. 2014;129:e521-643.

13. Zoghbi WA, Enriquez-Sarano M, Foster E, Grayburn PA, Kraft CD, Levine RA, et al. American Society of Echocardiography. Recommendations for evaluation of the severity of native valvular regurgitation with two- dimensional and Doppler echocardiography. J Am Soc Echocardiogr. 2003; 16:777-802.

14. Machino-Ohtsuka T, Seo Y, Ishizu T, Sato K, Sugano A, Yamamoto M, et al. Novel mechanic insights into atrial functional mitral regurgitation - 3dimensional echocardiographic study. Circ J. 2016;80:2240-8.

15. Ito K, Abe Y, Takahashi Y, Shimada Y, Fukumoto H, Matsumura Y, et al. Mechanism of atrial functional mitral regurgitation in patients with atrial fibrillation: a study using three-dimensional transesophageal echocardiography. J Cardiol. 2017;70:584-90.

16. Falk V, Baumgartner H, Bax JJ, De Bonis M, Hamm C, Holm PJ, et al. 2017 ESC/EACTS guidelines for the management of valvular heart disease. Eur J Cardiothorac Surg. 2017;52:616-64.

17. Gertz ZM, Raina A, Saghy L, Zado ES, Callans DJ, Marchlinski FE, et al. Evidence of atrial functional mitral regurgitation due to atrial fibrillation: reversal with arrhythmia control. J Am Coll Cardiol. 2011:58:1474-81.

18. Kagiyama N, Mondillo S, Yoshida K, Mandoli GE, Cameli M. Subtypes of atrial functional mitral regurgitation: imaging insights into their mechanisms and therapeutic implications. JACC Cardiovasc Imaging. 2020;13:820-35.

19. Beppu S, Kawazoe K, Nimura Y, Nagata S, Park YD, Sakakibara H, et al. Echocardiographic study of abnormal position and motion of the posterobasal wall of the left ventricle in cases of giant left atrium. Am J Cardiol. 1982:49:467-72.

20. Zhou X, Otsuji Y, Yoshifuku S, Yuasa T, Zhang H, Takasaki K, et al. Impact of atrial fibrillation on tricuspid and mitral annular dilatation and valvular regurgitation. Circ J. 2002;66:913-6.

21. Ravelli F, Allessie M. Effects of atrial dilatation on refractory period and vulnerability to atrial fibrillation in the isolated Langendorff-perfused rabbit heart. Circulation. 1997:96:1686-95.

22. Wang W, Buehler D, Martland AM, Feng XD, Wang YJ. Left atrial wall tension directly affects the restoration of sinus rhythm after maze procedure. Eur J Cardiothorac Surg. 2011:40:77-8.

\section{Publisher's Note}

Springer Nature remains neutral with regard to jurisdictional claims in published maps and institutional affiliations.

Ready to submit your research? Choose BMC and benefit from:

- fast, convenient online submission

- thorough peer review by experienced researchers in your field

- rapid publication on acceptance

- support for research data, including large and complex data types

- gold Open Access which fosters wider collaboration and increased citations

- maximum visibility for your research: over $100 \mathrm{M}$ website views per year

At BMC, research is always in progress.

Learn more biomedcentral.com/submissions 